\title{
The involvement of DARPP-32 in the pathophysiology of schizophrenia
}

\author{
Haitao Wang ${ }^{1,2, *}$, Mohd Farhan ${ }^{1, *}$, Jiangping Xü ${ }^{2}$, Philip Lazarovici ${ }^{3}$ and Wenhua Zheng ${ }^{1}$ \\ ${ }^{1}$ Faculty of Health Sciences, University of Macau, Taipa, Macau, China \\ ${ }^{2}$ School of Pharmaceutical Sciences, Southern Medical University, Guangzhou, China \\ ${ }^{3}$ School of Pharmacy Institute for Drug Research, Faculty of Medicine, The Hebrew University of Jerusalem, Jerusalem, Israel \\ *These authors contributed equally to this work
}

Correspondence to: Wenhua Zheng, email: wenhuazheng@umac.mo

Keywords: schizophrenia, DARPP-32, dopamine, CAMP, glutamate

Received: February 23, $2017 \quad$ Accepted: April 12, 2017

Published: April 21, 2017

Copyright: Wang et al. This is an open-access article distributed under the terms of the Creative Commons Attribution License 3.0 (CC BY 3.0), which permits unrestricted use, distribution, and reproduction in any medium, provided the original author and source are credited.

\section{ABSTRACT}

Schizophrenia is one of the most devastating heterogeneous psychiatric disorders. The dopamine hypothesis is the longest standing pathoetiologic theory of schizophrenia based on neurochemical evidences of elevated brain striatal dopamine synthesis capacity and increased dopamine release in response to stress. Dopamine and cyclic AMPregulated phosphoprotein of relative molecular mass 32,000 (DARPP-32) is a cytosolic protein highly enriched in the medium spiny neurons of the neostriatum, considered as the most important integrator between the cortical input and the basal ganglia, and associated with motor control. Accumulating evidences has indicated the involvement of DARPP-32 in the development of schizophrenia; $i$. DARPP-32 phosphorylation is regulated by several neurotransmitters, including dopamine and glutamate, neurotransmitters implicated in schizophrenia pathogenesis; ii. decrease of both total and phosphorylated DARPP-32 in the prefrontal cortex are observed in schizophrenic animal models; iii. postmortem brain studies indicated decreased expression of DARPP-32 protein in the superior temporal gyrus and dorsolateral prefrontal cortex in patients with schizophrenia; iv. DARPP-32 phosphorylation is increased upon therapy with antipsychotic drugs, such as haloperidol and risperidone which improve behavioral performance in experimental animal models and patients; v. Genetic analysis of the gene coding for DARPP-32 propose an association with schizophrenia. Cumulatively, these findings implicate DARPP-32 protein in schizophrenia and propose it as a potential therapeutic target. Here, we summarize the possible roles of DARPP-32 during the development of schizophrenia and make some recommendations for future research. We propose that DARPP-32 and its interacting proteins may serve as potential therapeutic targets in the treatment of schizophrenia.

\section{INTRODUCTION}

Schizophrenia is a severe mental disorder with a worldwide lifetime risk of approximately $1 \%$ of the population. This schizophrenic syndrome is characterized by cumulative psychiatric deficits including positive symptoms (e.g. delusions, hallucinations, and disorganized thought speech and /or behavior) and negative symptoms (e.g. affective flattening, lack of motivation, poor relatedness and social withdrawal) causing impairments of working and semantic memory $[1,2]$. The accurate causes and mechanisms of this idiopathic disorder are still unknown. It is hypothesized that genetic, environmental insults and vulnerability factors combine and interact with each other at critical periods of neurodevelopment and thus, alter the morphologies and physiological functions of neurons in specific brain regions [3-5], contributing to this mental disorder. Schizophrenic patients also suffer disproportionately from mood symptoms and are characterized by a significant risk of suicide [6]. Schizophrenia has been also considered as a neurodevelopmental disorder [7, 8]. 
To date, many hypotheses have been proposed to explain the disease, including dopamine hypothesis [9], inflammation and the neural diathesis-stress hypothesis [10], neurodevelopmental hypothesis [11] and glutamate hypothesis [12]. Among these multiple hypotheses, the dopamine hypothesis is the most accepted and longest standing pathoetiologic theory of schizophrenia [13], for more than several decades. The dopamine hypothesis was established based on several lines of evidences: i. clinical studies found that dopaminergic agonists could induce psychosis in normal individuals and could worsen psychosis in patients suffering from schizophrenia; ii. antipsychotic drugs blocked the dopamine receptors and their potency is linked to their affinity for dopamine D2 receptors, linking this receptor subtype to phenotype traits observed in patients; iii. postmortem studies provided direct evidence for elevated levels of dopamine, its metabolites, and its receptors in the striatum of schizophrenic patients [13].

Brain dopaminergic neuronal pathways are critical in maintaining multiple functions, including movement, rewards and stress [14]. Changes in neuronal circuits function can be regulated by dopaminergic receptorreceptor homologous and heterologous interactions, such as interaction between dopamine 1-like receptor (D1R) and dopamine 2-like receptor (D2R), or interaction with other signaling proteins inside the cell, or cross talk with heterologous receptors [15]. Dopamine receptors are divided into two families, D1R and D2R [16]. Both families belong to G-protein coupled receptors (GPCRs), which are linked to adenylyl cyclase (AC), that converse adenosine triphosphate (ATP) to cyclic adenosine monophosphate (cAMP). Specifically, D1Rs are coupled to Gs (stimulatory G-protein) and D2Rs are coupled to Gi (inhibitory G-protein). Activation of Gs-protein increases cAMP, while activation of Gi leads to the reduction of cAMP level [17]. cAMP in turn, activates cAMPdependent protein kinase A which phosphorylates a large number of protein substrates, such as phospholipases, protein kinases, tyrosine kinase receptors and ion channels located within the plasma membrane [18].

One well-studied target for the phosphorylation activity of dopamine receptors is "Dopamine and cAMPregulated phosphoprotein" of relative molecular mass 32,000 daltons (DARPP-32). DARPP-32, also known as phosphoprotein phosphatase-1 regulatory subunit $1 \mathrm{~B}$ (PPP1R1B), was initially found as a substrate of protein kinase A (PKA), activated by dopamine receptors D1R in the brain neostriatum [19]. In the central nervous system (CNS), DARPP-32 is expressed in medium spiny neurons (MSNs) that also co-express dopamine D1R [20] and containseveral sites forregulatory phosphorylations. Dopamine stimulates phosphorylation of DARPP-32 substrate at Thr34 residue by binding to D1R and subsequent activation of PKA [21]. DARPP-32, when phosphorylated at another site, Thr75, by cyclin- dependent kinase 5 (CDK5), is converted into an inhibitor of PKA [22]. Targeted deletion of the DARPP-32 gene in the mouse brain produced an altered biochemical and behavioral phenotype similar to schizophrenia [23]. Dopamine exerts a bidirectional control on the state of phosphorylation of DARPP-32. On one hand, activation of D1R increased the phosphorylation of DARPP-32 and activation of $\mathrm{D} 2 \mathrm{R}$ decreased basal phosphorylation of DARPP-32 [24]. On the other hand, DARPP-32 is involved in regulating dopamine receptor-induced transcription of several physiologically important genes in striatum and in globus pallidus, such as such as $c$-fos and NGFI-A [25]. The link between DARPP-32 and mental disorders, especially schizophrenia, has aroused extensive interest. Here, we review some of the current evidences and new ideas that are proposing DARPP-32 involvement in schizophrenia and suggest a few possibilities for future investigations.

\section{Expression of darpp-32 in the central nervous system}

Neuronal enzymes and their regulators and substrates play a fundamental role in brain function. On one hand, they are under the control of gene transcription, but they are also regulated by post-translational activities, such as phosphorylation and translocation to subcellular organelles. DARPP-32 is expressed at low levels prenatally, with the onset at day 14 of gestation in the rostral part of the primordial olfactory tubercle [26]. On day 18 of gestation, DARPP-32-immunoreactive neurons are first visible in the brain nucleus accumbens which, together with the olfactory tubercle, forms the ventral striatum, is part of the basal ganglia involved in cognitive processing of aversion, motivation, reward and addiction. The expression of DARPP-32 is gradually increased during brain development with strongly labeled neurons observed at the day of birth, reaching maximal expression 3 weeks postnatally [26]. Within the brain, DARPP-32 is mainly expressed in caudate, putamen, nucleus accumbens, cerebral and cerebellar cortex, all of these regions receiving dopaminergic projections and therefore involved in the pathogenesis of the schizophrenic disease [27]. At a cellular level, DARPP-32 protein is expressed in neuronal cell bodies and dendrites [28]. Specifically, DARPP-32 is present in the subclasses of dopaminergic neurons containing D1R, so, DARPP-32 is deemed to be a representative marker for striatal projection neurons [29].

Glutamatergic neurotransmission, including NMDA and other glutamatergic receptors have been involved in schizophrenia [30]. There are evidences that NMDA hypofunction disrupts the inhibitory/excitatory homeostasis and thereby leads to enhanced dopamine release from presynaptic dopaminergic neurons [13, 31].Therefore is not surprising that DARPP-32 also acts as an integrator of dopaminergic and glutamatergic input signaling [20]. 
Dopamine receptors D1R and the N-methyl-D-aspartate glutamate receptors (NMDAR) are involved in the prefrontal dysfunction linked with schizophrenic illness [31]. Interestingly, these two receptors antagonistically modulate the phosphorylation of DARPP-32 [32], probably attributed to the different $G$ proteins coupling these receptors to the adenylate cyclase and regulation the concentration of cAMP and activity of PKA. Modulation of DARPP-32 protein phosphorylation by dopamine and NMDA receptors is presented in Figure 1. The physiological consequences of this antagonistic modulation of DARPP-32 is expressed on its critical role in synaptic plasticity [33], and glutamatergic transmission [33] in which activation of DARPP-32 is required for the induction of both long-term depression (LTD) and longterm potentiation (LTP) [33] basic processes involved in learning and memory [34].

In the mammalian brain, PPP1R1B gene encodes two different transcripts of DARPP-32 protein, a full length DARPP-32 and a truncated DARPP-32. Truncated transcript encodes a protein that lacks the first 36 residues of N-terminus, which contains the phosphorylation site Thr 34 and the PP-1 interacting domain [35], and therefore cannot be phosphorylated by PKA and has no effect on PP-1. Truncated DARPP-32 form is only detected in adult brain striatal neurons in which the protein expression levels is higher than those of the full length
DARPP-32 [35]. As truncated DARPP-32 lacks the PP-1 interacting domain, the biological functions of full length and truncated DARPP-32 proteins might be different. Truncated DARPP isoform in MSNs might be necessary for the specification and connectivity establishment of the different neuronal subtypes, but less required for mature circuitry formation [35]. The protein level of truncated DARPP-32 is significantly increased in the dorsolateral prefrontal cortex and caudate of patients with schizophrenia $[36,37]$. The mechanism and role of the late developmental expression of truncated DARPP-32 in the CNS is yet unknown, and deserves further exploration.

\section{Regulation of darpp-32 by kinases and phosphatases in the central nervous system}

The activity of DARPP-32 depends on the state of phosphorylation at multiple regulatory sites, including Thr34, Thr75, Ser97 and Ser130. Phosphorylation of DARPP-32 by protein kinases and phosphatases is schematically presented in Figure 2. DARPP-32 can be activated by various neurotransmitters, including dopamine, glutamate, serotonin and adenosine [20, 38-40]. Dopamine regulates the phosphorylation of DARPP-32 through binding to D1R receptors which activates PKA. PKA in turn promotes the phosphorylation of DARPP-32 at Thr34, leading to its conversion into an inhibitor of

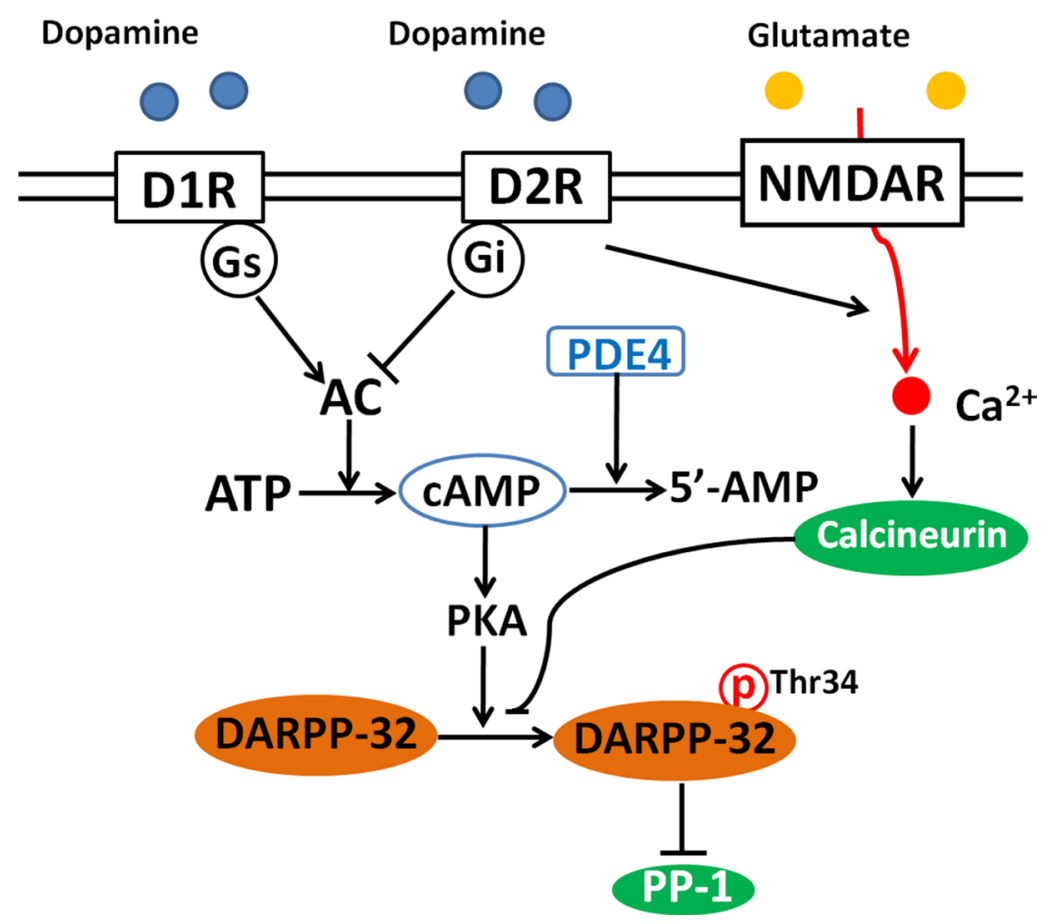

Figure 1: Modulation of DARPP-32 by dopamine and NMDA receptors. Binding of dopamine with D1 receptors (D1R) activates adenylate cyclase (AC) and increases intracellular cAMP, leading to the activation of PKA and the subsequent phosphorylation of DARPP-32 at Thr34. Activation of D2 receptors (D2R) inhibits AC, decreases the level of cAMP and DARPP-32 phosphorylation. Activation of NMDA receptor leads to increased intracellular calcium and activates calcium-dependent calcineurin, which promotes the dephosphorylation of DARPP-32 at Thr34. Phosphodiesterase 4 (PDE4) is an enzyme responsible for the hydrolysis of cAMP. Inhibition of PDE4 is supposed to enhances CAMP and thereby activates PKA. 
protein phosphatase 1(PP-1) [21]. PP-1 dephosphorylates a large number of neuronal phosphoproteins, and therefore DARPP-32-mediated inhibition of PP-1, inhibited or reduced the phosphorylation of proteins involved in synaptic function and plasticity [20]. Similar to activation of $\mathrm{D} 1 \mathrm{R}$, binding of adenosine to $\mathrm{A} 2 \mathrm{~A}$ receptor also leads to increased level of cAMP, activation of PKA and increased phosphorylation of DARPP-32 at Thr34 [41]. Since activation of adenosine A2A receptors can enhance the release of several neurotransmitters including dopamine [42], this common phosphorylation effect may amplify DARPP-32 synaptic activity. It is rather remarkable that activation of $\mathrm{D} 1 \mathrm{R}$ increases AC activity and thereby increasing DARPP-32 phosphorylation at Thr34 [24], while activation of the D2R on neostriatal neurons decreases AC activity and the formation of cAMP, and therefore decreases DARPP-32 phosphorylation at Thr34 [43]. When D2R receptors are co-expressed with adenosine $\mathrm{A} 2 \mathrm{~A}$ receptor, it can also result in a strong decrease of cAMP levels, inhibiting the activity of both PKA and in phosphorylation of DARPP-32 at Thr34 [44]. The opposite regulation exerted by A2A receptors and D2R receptors on DARPP-32 phosphorylation could explain some of the antagonistic actions of dopamine and adenosine in schizoprenia.

It was also reported that activation of D2R increased the neuronal influx of $\mathrm{Ca}^{2+}$ and the activity of calciumdependent protein phosphatase PP2B (named calcineurin), leading to dephosphorylation of DARPP-32 [24]. Activation of the N-methyl-D-aspartate glutamate receptors also leads to the activation of calcineurin and reverses the cAMP-induced phosphorylation of
DARPP-32 in striatum [45]. Blocking the activation of $\mathrm{D} 2 \mathrm{R}$ in the striatum, promotes the phosphorylation of DARPP-32 at Thr34 and can be reversed by inhibiting either D1R or A2A receptors [46]. Adenosine A2A receptors (A2AR) located in the postsynaptic membrane in the striato-pallidal GABAergic neurons, antagonize the biological function of dopamine D2 receptors, while A2AR receptors expressed presynaptically at corticostriatal terminals usually promotes glutamate release. Therefore it is tempting to propose that $\mathrm{A} 2 \mathrm{~A}$ receptors cause fine-tune striatal activity by integrating DARPP-32 mediated dopaminergic and glutamatergic signaling [41].

Besides phosphorylation at Thr34 by PKA, DARPP-32 is also phosphorylated by cyclin-dependent kinase 5 (CDK5) at Thr75, converting DARPP-32 into a PKA inhibitor [22]. Activation of NMDA receptors decreases the phosphorylation of DARPP-32 at Thr75, and this effect is mediated through calcium-dependent activation of protein phosphatase-2A (PP2A) [47, 48]. Hence, glutamate increases the phoshorylation and activity of DARPP-32 at Thr34 or Thr75 through activating different calcium-dependent protein phosphatases. Another complexity of calcium regulation is the calcium activation effect on protein kinase $\mathrm{C}$ (PKC) and $\mathrm{Ca}^{2+} /$ calmodulindependent protein kinase II (CaMK II). Activation of these kinases also results in DARPP32-Thr75 phosphorylation [49]. Therefore, different protein kinases and phosphatases activated by glutamate receptors dynamically modulate the phosphorylation of DARPP32-Thr75 site [49].

Casein kinase 1 (CK1) and casein kinase 2 (CK2) are additional protein kinases inducing the phosphorylation of DARPP-32. CK2 phosphorylates

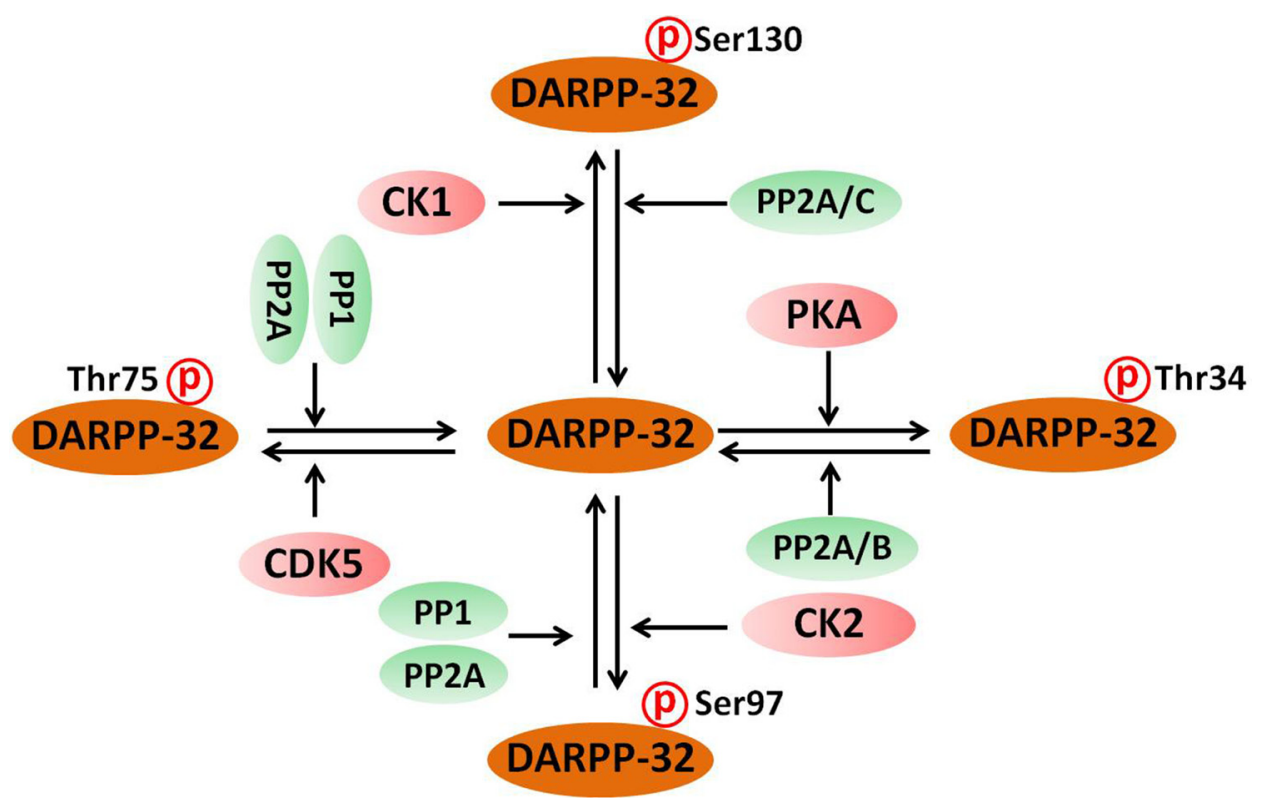

Figure 2: Phosphorylation of DARPP-32 by protein kinases and phosphatases. DARPP-32 is phosphorylated by PKA, CDK5, CK1 and CK2 protein kinases at different phosphorylation sites. On the other hand, DARPP-32 is dephosphorylated by protein phosphatase 1 (PP-1) protein phosphatase 2A (PP2A) and calcineurin (PP2B). 
DARPP-32 at Ser97, while CK1's phosphorylation site is Ser130 [50]. Phosphorylation of DARPP-32 at Ser97 promotes the phosphorylation of DARPP-32 at Thr34 by cAMP-dependent PKA [51] and phosphorylation of Ser137 by CK1 decreases dephosphorylation of Thr34 by calcineurin [52]. Phosphorylation of DARPP-32 by CK1 and CK2 occurs in response to increased levels of cAMP [51]. It is also known that activation of D1R/ PKA signaling activates PP2A/B56 $\delta$, and promotes the dephosphorylation of DARPP-32 at Ser97, eventually reducing the export of DARPP-32 out of the nucleus [53]. Cytonuclear trafficking of DARPP-32 may be important to the biological functions of dopamine on striatal neurons. Following activation of D1R, DARPP-32 is accumulated in the nucleus of dopaminergic neurons and this facilitates the phosphorylation of histone $\mathrm{H} 3$ at Ser10, a site dephosphorylated by PP1, suggesting that DARPP-32 is involved in the regulation of alternative splicing or gene expression [54]. Recently, DARPP-32 Ser97 phosphorylation was reported to mediate the binding of DARPP-32 to $\beta$-adducin, an actin-capping protein that stabilizes the neuronal cytoskeleton, and this effect was reinforced by DARPP-32 Thr75 phosphorylation [55]. As $\beta$-adducin increases the density of neuronal dendritic spines under the conditions of novel enriched environment, DARPP-32 is viewed as a regulator of rapid neuronal modifications induced by environment, to enforce learning and memory [55].

The phosphorylation state of DARPP-32 is determined by both protein kinases and phosphatases. As shown in Figure 2, there are four major phosphorylation sites for DARPP-32. i. Phospho-Thr34, the site phosphorylated by PKA, is dephosphorylated by both PP2A and $\mathrm{PP} 2 \mathrm{~B}$ (calcineurin) [56]. PP2A is a heterotrimeric enzyme composed of PKA-sensitive PP2A/B56 $\delta$ and $\mathrm{Ca}^{2+}$-sensitive PP2A/PR72 [57]. The heterotrimeric form of PP2A that includes the B56 $\delta$ subunit is involved in the dephosphorylation of DARPP-32 at Thr34 [58]. Activation of PP2A by PKA leads to the shutting off of D1R/PKA/PThr34 DARPP-32 signaling [59]. Thr34 dephosphorylation by PP2B leads to disinhibition of PP1 [24]. ii. PhosphoThr75 is dephosphorylated by PP1, PP2A and PP2C, and $\mathrm{PP} 2 \mathrm{~A}$ is the major phosphatase acting on this site [47]. Both PP2A/B56 $\delta$ and PP2A/PR72 are effective in mediating the dephosphorylation of DARPP-32 at Thr-75 [47]. Dephosphorylation of DARPP-32 at Thr75 relieves the inhibition of PKA [22]. iii. Phospho-Ser97 DARPP-32 is dephosphorylated by PP1 and PP2A. Dephosphorylation of DARPP-32 at Ser97 by PP2A causes nuclear localization of DARPP-32 [60]. However, the effect of PP1 on the dephosphorylation of P-Ser97 DARPP-32 and the subsequent functions are not yet well defined. iv. Phosphor-Ser130 DARPP-32 is dephosphorylated by PP2A and PP2C. The phosphorylation of DARPP-32 at Ser130 stimulated by CK-1 has been implicated in the biological action of mGluR1/5 receptors [61]. However, the biological roles of PP2A and PP2C in dephosphorylation of DARPP-32 at Ser130 have not yet been identified.

\section{Alteration and activity changes of darpp-32 in animal models of schizophrenia}

As described above, it has long been suggested that brain mesocorticolimbic dopaminergic system dysfunction, expressed by increase in dopamine levels or dopamine receptor sub-types expression levels, are involved in the pathogenesis of schizophrenia. Based on this theory, current antipsychotic drugs act as the pharmacological antagonists of D2R. The schizophrenic behavior may be expressed in a specific animal phenotype and may be analyzed under controlled conditions in the laboratory. For example, amphetamine, by increasing synaptic monoamine levels, can induce psychotic-schizophrenic like symptoms including reduced social behavior $[62,63]$, deficits in pre-pulse inhibition and increased locomotor activity [64]. In amphetamine-induced animal model of schizophrenia, the increased total protein levels of CDK5, p35 and p25 proteins resulted in increased CDK5 kinase activity and subsequently increased the phosphorylation of DARPP-32 at Thr75 site in the brain nucleus accumbens [65]. These results indicate that chronic hyperdopaminergic situation may increase the activity of DARPP-32.

The glutamate hypothesis of schizophrenia based on NMDA receptor hypofunction arose from the observation that administration of noncompetitive NMDAR antagonists, such as phencyclidine (PCP) or ketamine, to healthy individuals, induces hallucinations, delusions, negative symptoms and cognitive impairment that mimic schizophrenia, and exacerbates those symptoms in schizophrenic patients [66]. Administration of PCP in mice with conditional knockout of DARPP-32 in the GABAergic medium spiny neurons enhances DARPP-32 phosphorylation at Thr34 in the striatum [67], and the localization of this effect is preferentially in the MSNs expressing D1R of the direct pathway [68]. Conditional knockout of DARPP-32 in the MSNs abolished the motor stimulatory effects of PCP, while the memory deficits induced by PCP were not associated with the expression of DARPP-32 [68].

Considering findings from schizophrenic animal models, we can conclude that increased phosphorylation of DARPP-32 and its downstream effectors have a causative role in schizophrenia. These changes are associated with the behavioral responses in animals, and can be regarded as a surrogate marker of the positive schizophrenic symptoms [68]. This conclusion is also supported by studies indicating that learning is impaired 
in calcineurin knockout mice, establishing a link between synaptic anomalies and cognitive impairment observed in schizophrenic mice models [69]. Since DARPP-32 is a major substrate of calcineurin, this is another indirect link to its involvement in schizophrenia.

\section{Alteration of darpp-32 in schizophrenic patients}

In human patients with schizophrenia, DARPP-32 was significantly decreased in the dorsolateral prefrontal cortex circuit (DLPFC) [32], A postmortem study showed a significant decrease of DARPP-32 in the DLPFC of patients with schizophrenia, and the decrease of DARPP-32 was associated with dysfunction of dopaminergic neurons $[70,71]$. Moreover, the density of DARPP-32-positive neurons was significantly decreased in layers II-V of the DLPFC [72]. By contrast, the level of phosphorylated DARPP-32 (Thr34) in neurons of layer $\mathrm{V}$ of DLPFC was significantly higher [72]. These results are supported by the findings that both the protein level of DARPP-32 and the phosphorylation of DARPP-32 (Thr34) were found significantly lower in the brain superior temporal gyrus of the schizophrenic patients [73]. The density of DARPP-32-positive neurons in the layers II and III of the brain rostral agranular insular cortex was significantly decreased in the schizophrenic group compared with the healthy control group [74]. Cumulatively, these findings indicate that the levels of DARPP-32 protein expression and phosphorylation are decreased in the prefrontal cortex of schizophrenic patients. Interestingly, the other form of DARPP-32, the truncated DARPP-32 protein, is significantly increased in the DLPFC and caudate of patients with schizophrenia $[36,37]$. Although no explanation is available, these data support the hypothesis that prevalence of DARPP-32 is associated with the pathogenesis of disease in the schizophrenic patients.

Unfortunately, there are on this topic inconclusive reports as well. No change in DARPP-32 protein levels were found in schizophrenic prefrontal and cingulate cortex and $\mathrm{T}$ lymphocytes of elderly patients with schizophrenia [75, 76]. Mutation analysis of DARPP-32 gene indicate that it is not a major susceptibility gene for schizophrenia [77]. In the sight of genetic analyses, no allelic, genotypic or haplotypic association between DARPP-32 and schizophrenia was found in the Chinese population [78], which was consistent with the findings that DARPP-32 are unlikely to be the risk factor of schizophrenia in the Japanese and Malay population [79, 80]. The explanations for these conflicting results remain to be elucidated. It is possible that DARPP-32 contributes to schizophrenia by interacting with other genes, such as dopamine D2 receptor gene and ankyrin-repeat containing kinase 1 gene [36] or other possibilities addressed in the next paragraphs.

\section{Effects of antipsychotic drugs on darpp-32 signaling}

Dopamine D2R is the main target of antipsychotic drugs used for schizophrenia therapy. Chronic blockade of either D1R by SCH-23390 or D2R by raclopride does not increase the level of expression of DARPP-32 protein in specific rat brain regions, including striatum, thalamus, hippocampus and frontal cerebral cortical pole [81]. However, blockade of D2R by typical antipsychotic drugs such as the butyrophenone haloperidol, or the newer antipsychotic drug clozapine, increased the phosphorylation of DDARPP-32 at PKA site [82]. These data indicate that typical or atypical antipsychotic drugs have no effect on the protein or mRNA expression of DARPP-32, but they increase the phosphorylation of DARPP-32. Interestingly, both psychostimulant and antipsychotic drugs have similar effects on the phosphorylation of DARPP-32 at Thr34 site. Chronic administration of psychostimulant cocaine increases the phosphorylation of DARPP-32 (Thr34) and the expression of transcription factor DeltaFosB in the ventral striatum [83]. Paradoxaly, administration of D2R antagonist haloperidol also increases the phosphorylation of DARPP-32. Since these drugs have opposing behavioral and clinical effects, this paradox may be explained by the drug effect on different types of neuronal pathways or different brain structures. Cell-type specific analysis of DARPP-32 phosphorylation in striato-nigral and striatopallidal neurons indicated that cocaine selectively enhanced the phosphorylation of DARPP-32 at Thr34 selectively in striato-nigral neurons, while haloperidol stimulated the phosphorylation of DARPP-32 at Thr34 only in striatopallidal neurons [84]. Therefore, cocaine effect is exerted through D1R-mediated activation of AC, which is also called direct MSN pathway. In contrast, the effect of haloperidol is exerted through blockade of D2Rs and disinhibition of $\mathrm{AC}$ in MSNs, which is called the indirect pathway [84, 85]. Moreover, in the striato-pallidal neurons, blockade of D2Rs by antipsychotic drugs inhibited adenosine $\mathrm{A} 2$ receptorsmediated activation of cAMP signaling, leading to increased level of intracellular cAMP and activation of PKA $[85,86]$.

Nurr77 is an immediate-early gene of the nuclear receptor super family, which is highly expressed in the brain prefrontal cortex, dorsal striatum, and nucleus accumbens. Several investigations indicate that Nurr77 mediates biological effects of dopamine receptors blockade or stimulation. Nur77 is also involved in the antipsychotic motor lateral effects of antipsychotic agents $[87,88]$. It has been shown that haloperidol increases the expression of Nur77 in D2R- but not D1R-expressing neurons, and importantly, Nur77 induction by haloperidol was prevented in T34A DARPP-32 knock mutant mice model, indicating that expression of Nur77 in striatopallidal neurons is mediated by DARPP-32 -dependent regulation of PP-1 [87]. 


\section{Potential relationships between neurotrophins and darpp-32 gene polymorphisms}

Neurotrophins, particularly brain-derived neurotrophic factor (BDNF) and nerve growth factor (NGF), are crucial mediators involved in the regulation of neuronal survival, proliferation, differentiation, neurodevelopment and maintenance of neurons in the central and peripheral nervous systems [89-91]. The neurodevelopment hypothesis of schizophrenia is based on the findings of: i. decreased plasma and serum BDNF [92] and NGF [93] levels in schizophrenic patients; ii. BDNF promotes the development of brain mesolimbic dopaminergic system, BDNF synthesized by dopamine neurons influences the expression of dopamine D3 receptors [94]; iii. NGF is maintaining and regulating the phenotype and neuronal circuits of cholinergic neurons, and thereby involved in the process of learning and memory [95]. iv. Low expression of NGF in prefrontal cortex and low levels of BDNF in hippocampus, measured in rodent models of schizophrenia, may indicate that they are associated with cognitive impairment during disease progress and its therapy with antipsychotic drugs [95]. Moreover, BDNF received the most attention in suicide research indicating reduced levels in blood cells of suicidal patients and in brains of patients who committed suicide [96] and a strong link was found between suicidal behavior in schizophrenic patients and BDNF functional polymorphism [97]. Therefore, genes involved in the dopamine pathway such as BDNF and DARPP-32 and their possible association, are biologically plausible candidates in schizophrenic patients with suicide attempts.

The most extensively single nucleotide polymorphism (SNP) studies of BDNF gene is rs6265, which produces a $\mathrm{G} / \mathrm{A}$ amino acid substitution (valine to methionine) at codon 66 (Val66Met) [98]. This functional polymorphism caused behavioral changes, including anxiety and depression in a genetically engineered mice and may impair human memory and hippocampal function [99]. Preliminary association studies between the functional SNP Val66Met and schizophrenia have generated conflicting results. A positive association was found in a family study in Italian subjects [100]. Patients carrying at least one copy of the minor allele Val66Met functional BDNF marker have attempted suicides compared to patients with other genotypes and non-suicidal patients [101]. In another study it was found that BDNF Val66Met allele is an independent predictor or risk factor of suicide attempts of depressed patients [96]. In a recent meta-analysis study, a significant association was found between BDNF Val66Met polymorphism and schizophrenia, with pooled results indicating no significant evidence for the association of $\mathrm{Val} / \mathrm{Val}$ and $\mathrm{Val} / \mathrm{Met}$ genotypes of BDNF gene with disease. However, it was observed that there is a significant association between Met/Met polymorphism and schizophrenia in Asian,
European, and Chinese populations, suggesting that the risk of schizophrenia in these populations with Met/Met genotype, is 9,26 , and $9 \%$, respectively [102]. In line with these findings, a recent study demonstrated association of schizophrenia with the rs6330, rs4839435 and rs734194, rs11466155, rs2072446 functional SNPs of genes encoding NGF and NGF receptor [103]. Reduced expression of DARPP-32 has been observed in the postmortem brain of schizophrenic patients [32]. This finding was suggested to be related to the abnormalities observed in patients with schizophrenia, e.g., activation, neostriatal volume, and functional connectivity in the prefrontal cortex [104]. Five molecular variants of DARPP-32 were identified: 1. a C-to-G substitution at nucleotide position -2036 (g.$2036 \mathrm{C}>\mathrm{G}) ; 2$. Absence of $\mathrm{G}$ in the untranslated exon 2 (g.1238delG); 3.a G-to-A and 4.an A-to-G substitutions in intron $2($ IVS $2+31 \mathrm{G}>A$ ) and intron $6($ IVS $6+32 A>G)$, respectively, and 5. deletion of a three-base pair (AGA) in exon 6 that led to the absence of a glutamate at codon 135 (E135del) [77]. In view of increase in variable analyses obtained from studies in world populations of schizophrenic patients, there is a need to examine the association between the BDNF Val66Met and the above five variants DARPP-32 - polymorphism.

Preclinical experiments demonstrated that BDNF elevates the temporal and perhaps spatial expression of DARPP-32 [105], and BDNF receptor (trkBtropomyosin receptor kinase $\mathrm{B}$ )signaling is thought to be the activator of DARPP-32 striatal expression [106]. $\mathrm{BDNF}^{-/}$mice showed delayed and decreased expression of DARPP-32, while BDNF treatment in vivo increases the level of DARPP-32 [105]. Further studies verified that both the phosphatidylinositol 3-kinase (PI3K)/protein kinase B (Akt) /mammalian target of rapamycin (mTOR) and the CDK5/p35 signaling pathways are involved in the regulation of DARPP-32 protein levels by BDNF in MSNs. [107]. The inherent weaknesses of these studies are likely confounded by clinical heterogeneity, effects of chronic illness and medications and have been limited by schizophrenic patient cohort size and the complex genetics involved in this disease. Therefore, future preclinical and clinical studies may significantly clarify the association between DARPP-32, BDNF and other genes polymorphism to elucidate the mechanisms of these genetic associations with schizophrenia illness in human brain [108].

\section{PERSPECTIVES AND CONCLUSIONS}

Dysfunction of dopamine system triggers a shift of the balance between the phosphorylation and dephosphorylation of DARPP-32, which is highly associated with abnormal psychiatric behavior. An adjustment of this imbalance is supposed to be beneficial for the treatment of CNS disorders, including schizophrenia [109]. Stimulation or blocking 
neurotransmitters' receptors is a practical pharmacological approach to promote the phosphorylation state of DARPP-32. On the other hand, the activity of DARPP-32 also depends on the level of intracellular cAMP. cAMP level is not only regulated by AC synthesis, but also by phosphodiesterases (PDEs) degradation of this second messanger. Therefore, inhibition of PDEs, such as PDE4, is a alternative strategy to stimulate the phosphorylation of DARPP-32 (Figure 1). Recently, it has been reported that inhibition of PDE4 by the drug rolipram activated cAMP/ PKA signaling and enhanced the phosphorylation of DARPP-32 in the frontal cortex [110]. However, approved PDE4 drug inhibitors such as cilomilast and roflumilast cause intolerable side effects, such as nausea and emesis [111]. Novel PDE4 inhibitors, such as chlorbipram and roflupram, which have little emetic potential and found effective as antidepressants and cognitive enhancers in animal experiments [111-113], are promising drugs for the clinical application in schizophrenia by targeting DARPP-32 phosphorylation. To the best of our knowledge, none of these novel PDE4 inhibitors have been tested in schizophrenic patients by clinical trials.

Currently, most of the medical translational studies focused on the phosphorylation state of DARPP-32, and they represent a promising direction [114]. On the other hand, we may also need to pay attention to the protein expression of DARPP-32 in the brain, especially in the brain regions highly related to schizophrenia. Postmortem studies show a significant reduction of DARPP-32 in the schizophrenic brain $[70,71]$ as also observed in prenatal LPS-induced animal model of schizophrenia [115]. Therefore, from a pharmacological point of view, increasing the expression of DARPP-32 may be beneficial for schizophrenia therapy. It is interesting that BDNF promotes the expression of DARPP-32 through $\mathrm{PI} 3 \mathrm{~K} / \mathrm{Akt} / \mathrm{mTOR}$ sigaling pathway $[105,106]$, enhances neurodevelopment and neural plasticity [116-118] and corrects other deficits reported in schziphrenic patients $[119,120]$. We predict that future drug development protocols for schizophrenia will consider small molecules or biologics that specifically target DARPP-32 and its interacting proteins.

In conclusion, in the last three decades, scientific investigations have proved that DARPP-32 acts as a major integrator signaling phosphoprotein, activated by a diverse array of neurotransmitters, such as dopamine, glutamate, serotonin, adenosine, and gamma-aminobutyric acid in the CNS [114]. Importantly, current studies supported the involvement of DARPP-32 in the pathology of CNS disorders. The role of DARPP-32 proteins in schizophrenia has been recently recognized and aroused wide interests to unveil new functions of DARPP-32. Collectively, the present preclinical and clinical findings strongly suggest that DARPP-32 protein is a promising therapeutic target for the treatment of schizophrenia.

\section{ACKNOWLEDGMENTS AND FUNDING}

This research was supported by National Natural Science Foundation of China (No. 81301099, No. 31371088), Science and Technology Planning Project of Guangdong Province (No. 2011B050200005). SRG201500004-FHS and MYRG2016-00052-FHS from University of Macau, and the Science and Technology Development Fund (FDCT) of Macao (FDCT 021/2015/A1). PL holds The Jacob Gitlin Chair in Physiology and is affiliated and partially supported by Grass Center for Drug Design and Synthesis of Novel Therapeutics and The Adolph and Klara Brettler Medical Research Center at The Hebrew University of Jerusalem, Israel.

\section{CONFLICTS OF INTEREST}

The authors declare no conflicts of interest.

\section{REFERENCES}

1. Kuperberg G, Heckers S. Schizophrenia and cognitive function. Curr Opin Neurobiol. 2000; 10:205-210.

2. Zheng W, Wang H, Zeng Z, Lin J, Little PJ, Srivastava LK, Quirion R. The possible role of the Akt signaling pathway in schizophrenia. Brain Res. 2012; 1470:145-158.

3. Datta D, Arion D, Corradi JP, Lewis DA. Altered expression of CDC42 signaling pathway components in cortical layer 3 pyramidal cells in schizophrenia. Biol Psychiatry. 2015; 78:775-785.

4. Davis J, Eyre H, Jacka FN, Dodd S, Dean O, McEwen S, Debnath M, McGrath J, Maes M, Amminger P, McGorry PD, Pantelis C, Berk M. A review of vulnerability and risks for schizophrenia: Beyond the two hit hypothesis. Neurosci Biobehav Rev. 2016; 65:185-194.

5. Ramos-Miguel A, Barr AM, Honer WG. Spines, synapses, and schizophrenia. Biol Psychiatry. 2015; 78:741-743.

6. Hawton K, Sutton L, Haw C, Sinclair J, Deeks JJ. Schizophrenia and suicide: systematic review of risk factors. Br J Psychiatry. 2005; 187:9-20.

7. Karam CS, Ballon JS, Bivens NM, Freyberg Z, Girgis RR, Lizardi-Ortiz JE, Markx S, Lieberman JA, Javitch JA. Signaling pathways in schizophrenia: emerging targets and therapeutic strategies. Trends Pharmacol Sci. 2010; 31:381-390.

8. Bitanihirwe BK, Mauney SA, Woo TU. Weaving a Net of Neurobiological Mechanisms in Schizophrenia and Unraveling the Underlying Pathophysiology. Biol Psychiatry. 2016; 80:589-598.

9. Kambeitz J, Abi-Dargham A, Kapur S, Howes OD. Alterations in cortical and extrastriatal subcortical dopamine function in schizophrenia: systematic review and meta-analysis of imaging studies. Br J Psychiatry. 2014; 204:420-429. 
10. Howes OD, McCutcheon R. Inflammation and the neural diathesis-stress hypothesis of schizophrenia: a reconceptualization. Translational psychiatry. 2017; 7:e1024.

11. Schmidt MJ, Mirnics K. Neurodevelopment, GABA system dysfunction, and schizophrenia. Neuropsychopharmacology. 2015; 40:190-206.

12. Hu W, MacDonald ML, Elswick DE, Sweet RA. The glutamate hypothesis of schizophrenia: evidence from human brain tissue studies. Ann N Y Acad Sci. 2015; 1338:38-57.

13. Howes OD, McCutcheon R, Owen MJ, Murray RM. The Role of Genes, Stress, and Dopamine in the Development of Schizophrenia. Biol Psychiatry. 2017; 81:9-20.

14. Stievenard A, Mequinion M, Andrews ZB, Destee A, Chartier-Harlin MC, Viltart O, Vanbesien-Mailliot CC. Is there a role for ghrelin in central dopaminergic systems? Focus on nigrostriatal and mesocorticolimbic pathways. Neurosci Biobehav Rev. 2017; 73:255-275.

15. Missale C, Fiorentini C, Collo G, Spano P. The neurobiology of dopamine receptors: evolution from the dual concept to heterodimer complexes. J Recept Signal Transduct Res. 2010; 30:347-354.

16. Yamamoto K, Fontaine R, Pasqualini C, Vernier P. Classification of Dopamine Receptor Genes in Vertebrates: Nine Subtypes in Osteichthyes. Brain Behav Evol. 2015; 86:164-175.

17. Williams C. cAMP detection methods in HTS: selecting the best from the rest. Nat Rev Drug Discov. 2004; 3:125-135.

18. Neve KA, Seamans JK, Trantham-Davidson H. Dopamine receptor signaling. J Recept Signal Transduct Res. 2004; 24:165-205.

19. Walaas SI, Aswad DW, Greengard P. A dopamine- and cyclic AMP-regulated phosphoprotein enriched in dopamineinnervated brain regions. Nature. 1983; 301:69-71.

20. Svenningsson P, Nishi A, Fisone G, Girault JA, Nairn AC, Greengard P. DARPP-32: an integrator of neurotransmission. Annu Rev Pharmacol Toxicol. 2004; 44:269-296.

21. Hemmings HC Jr, Greengard P, Tung HY, Cohen P. DARPP-32, a dopamine-regulated neuronal phosphoprotein, is a potent inhibitor of protein phosphatase-1. Nature. 1984; 310:503-505.

22. Bibb JA, Snyder GL, Nishi A, Yan Z, Meijer L, Fienberg AA, Tsai LH, Kwon YT, Girault JA, Czernik AJ, Huganir RL, Hemmings HC Jr, et al. Phosphorylation of DARPP-32 by Cdk5 modulates dopamine signalling in neurons. Nature. 1999; 402:669-671.

23. Fienberg AA, Hiroi N, Mermelstein PG, Song W, Snyder GL, Nishi A, Cheramy A, O'Callaghan JP, Miller DB, Cole DG, Corbett R, Haile CN, Cooper DC, et al. DARPP-32: regulator of the efficacy of dopaminergic neurotransmission. Science. 1998; 281:838-842.

24. Nishi A, Snyder GL, Greengard P. Bidirectional regulation of DARPP-32 phosphorylation by dopamine. J Neurosci. 1997; 17:8147-8155.
25. Svenningsson $\mathrm{P}$, Fienberg AA, Allen PB, Moine CL, Lindskog M, Fisone G, Greengard P, Fredholm BB. Dopamine $\mathrm{D}(1)$ receptor-induced gene transcription is modulated by DARPP-32. J Neurochem. 2000; 75:248-257.

26. Foster GA, Schultzberg M, Hokfelt T, Goldstein M, Hemmings HC Jr, Ouimet CC, Walaas SI, Greengard P. Development of a dopamine- and cyclic adenosine $3^{\prime}: 5^{\prime}$-monophosphate-regulated phosphoprotein (DARPP-32) in the prenatal rat central nervous system, and its relationship to the arrival of presumptive dopaminergic innervation. J Neurosci. 1987; 7:1994-2018.

27. Brene S, Hall H, Lindefors N, Karlsson P, Halldin C, Sedvall G. Distribution of messenger RNAs for D1 dopamine receptors and DARPP-32 in striatum and cerebral cortex of the cynomolgus monkey: relationship to D1 dopamine receptors. Neuroscience. 1995; 67:37-48.

28. Ouimet CC, Miller PE, Hemmings HC Jr, Walaas SI, Greengard P. DARPP-32, a dopamine- and adenosine $3^{\prime}: 5$ '-monophosphate-regulated phosphoprotein enriched in dopamine-innervated brain regions. III. Immunocytochemical localization. J Neurosci. 1984; 4:111-124.

29. Petryszyn S, Sanchez MG, Gagnon D, Beaulieu JM, Parent A, Parent M. A dense cluster of D1 + cells in the mouse nucleus accumbens. Synapse. 2017; 71:51-54.

30. Hall J, Trent S, Thomas KL, O’Donovan MC, Owen MJ. Genetic risk for schizophrenia: convergence on synaptic pathways involved in plasticity. Biol Psychiatry. 2015; 77:52-58.

31. Howes O, McCutcheon R, Stone J. Glutamate and dopamine in schizophrenia: an update for the 21 st century. J Psychopharmacol. 2015; 29:97-115.

32. Albert KA, Hemmings HC Jr, Adamo AI, Potkin SG, Akbarian S, Sandman CA, Cotman CW, Bunney WE Jr, Greengard P. Evidence for decreased DARPP-32 in the prefrontal cortex of patients with schizophrenia. Arch Gen Psychiatry. 2002; 59:705-712.

33. Calabresi P, Gubellini P, Centonze D, Picconi B, Bernardi G, Chergui K, Svenningsson P, Fienberg AA, Greengard P. Dopamine and cAMP-regulated phosphoprotein $32 \mathrm{kDa}$ controls both striatal long-term depression and longterm potentiation, opposing forms of synaptic plasticity. J Neurosci. 2000; 20:8443-8451.

34. Qian Y, Forssberg H, Diaz Heijtz R. Motor Skill Learning Is Associated with Phase-Dependent Modifications in the Striatal cAMP/PKA/DARPP-32 Signaling Pathway in Rodents. PLoS One. 2015; 10:e140974.

35. Straccia M, Carrere J, Rosser AE, Canals JM. Human t-DARPP is induced during striatal development. Neuroscience. 2016; 333:320-330.

36. Kunii Y, Miura I, Matsumoto J, Hino M, Wada A, Niwa S, Nawa H, Sakai M, Someya T, Takahashi H, Kakita A, Yabe H. Elevated postmortem striatal t-DARPP expression in schizophrenia and associations with DRD2/ANKK1 polymorphism. Prog Neuropsychopharmacol Biol Psychiatry. 2014; 53:123-128. 
37. Kunii Y, Hyde TM, Ye T, Li C, Kolachana B, Dickinson D, Weinberger DR, Kleinman JE, Lipska BK. Revisiting DARPP-32 in postmortem human brain: changes in schizophrenia and bipolar disorder and genetic associations with t-DARPP-32 expression. Mol Psychiatry. 2014; 19:192-199.

38. Nishi A, Matamales M, Musante V, Valjent E, Kuroiwa M, Kitahara Y, Rebholz H, Greengard P, Girault JA, Nairn AC. Glutamate Counteracts Dopamine/PKA Signaling via Dephosphorylation of DARPP-32 Ser-97 and Alteration of Its Cytonuclear Distribution. J Biol Chem. 2017; 292:1462-1476.

39. Devroye C, Cathala A, Maitre M, Piazza PV, Abrous DN, Revest JM, Spampinato U. Serotonin2C receptor stimulation inhibits cocaine-induced Fos expression and DARPP-32 phosphorylation in the rat striatum independently of dopamine outflow. Neuropharmacology. 2015; 89:375-381.

40. Hsu CW, Chen CY, Wang CS, Chiu TH. Caffeine and a selective adenosine $\mathrm{A} 2 \mathrm{~A}$ receptor antagonist induce reward and sensitization behavior associated with increased phospho-Thr75-DARPP-32 in mice. Psychopharmacology. 2009; 204:313-325.

41. Shen HY, Canas PM, Garcia-Sanz P, Lan JQ, Boison D, Moratalla R, Cunha RA, Chen JF. Adenosine A(2)A receptors in striatal glutamatergic terminals and GABAergic neurons oppositely modulate psychostimulant action and DARPP-32 phosphorylation. PLoS One. 2013; 8:e80902.

42. Sebastiao AM, Ribeiro JA. Adenosine A2 receptor-mediated excitatory actions on the nervous system. Prog Neurobiol. 1996; 48:167-189.

43. Lindskog M, Svenningsson P, Fredholm BB, Greengard P, Fisone G. Activation of dopamine D2 receptors decreases DARPP-32 phosphorylation in striatonigral and striatopallidal projection neurons via different mechanisms. Neuroscience. 1999; 88:1005-1008.

44. Hara M, Fukui R, Hieda E, Kuroiwa M, Bateup HS, Kano T, Greengard P, Nishi A. Role of adrenoceptors in the regulation of dopamine/DARPP-32 signaling in neostriatal neurons. J Neurochem. 2010; 113:1046-1059.

45. Halpain S, Girault JA, Greengard P. Activation of NMDA receptors induces dephosphorylation of DARPP-32 in rat striatal slices. Nature. 1990; 343:369-372.

46. Svenningsson P, Lindskog M, Ledent C, Parmentier M, Greengard P, Fredholm BB, Fisone G. Regulation of the phosphorylation of the dopamine- and cAMP-regulated phosphoprotein of $32 \mathrm{kDa}$ in vivo by dopamine D1, dopamine D2, and adenosine A2A receptors. Proc Natl Acad Sci USA. 2000; 97:1856-1860.

47. Nishi A, Bibb JA, Matsuyama S, Hamada M, Higashi H, Nairn AC, Greengard P. Regulation of DARPP-32 dephosphorylation at PKA- and Cdk5-sites by NMDA and AMPA receptors: distinct roles of calcineurin and protein phosphatase-2A. J Neurochem. 2002; 81:832-841.

48. Andrade EC, Musante V, Horiuchi A, Matsuzaki H, Brody AH, Wu T, Greengard P, Taylor JR, Nairn AC. ARPP-
16 is a striatal-enriched inhibitor of protein phosphatase $2 \mathrm{~A}$ regulated by microtubule-associated serine/threonine kinase 3 (Mast 3 kinase). J Neurosci. 2017.

49. Kim J, Ryu IS, Seo SY, Choe ES. Activation of Protein Kinases and Phosphatases Coupled to Glutamate Receptors Regulates the Phosphorylation State of DARPP32 at Threonine 75 After Repeated Exposure to Cocaine in the Rat Dorsal Striatum in a Ca2+-Dependent Manner. Int J Neuropsychopharmacol. 2015; 18.

50. Zhang Y, Svenningsson P, Picetti R, Schlussman SD, Nairn AC, Ho A, Greengard P, Kreek MJ. Cocaine selfadministration in mice is inversely related to phosphorylation at Thr34 (protein kinase A site) and Ser130 (kinase CK1 site) of DARPP-32. J Neurosci. 2006; 26:2645-2651.

51. Girault JA, Hemmings HC Jr, Williams KR, Nairn AC, Greengard P. Phosphorylation of DARPP-32, a dopamineand cAMP-regulated phosphoprotein, by casein kinase II. J Biol Chem. 1989; 264:21748-21759.

52. Desdouits F, Cohen D, Nairn AC, Greengard P, Girault JA. Phosphorylation of DARPP-32, a dopamine- and cAMPregulated phosphoprotein, by casein kinase I in vitro and in vivo. J Biol Chem. 1995; 270:8772-8778.

53. Stipanovich A, Valjent E, Matamales M, Nishi A, Ahn JH, Maroteaux M, Bertran-Gonzalez J, Brami-Cherrier K, Enslen H, Corbille AG, Filhol O, Nairn AC, Greengard P, et al. A phosphatase cascade by which rewarding stimuli control nucleosomal response. Nature. 2008; 453:879-884.

54. Yger M, Girault JA. DARPP-32, Jack of All Trades. Master of Which? Front Behav Neurosci. 2011; 5:56.

55. Engmann O, Giralt A, Gervasi N, Marion-Poll L, Gasmi L, Filhol O, Picciotto MR, Gilligan D, Greengard P, Nairn AC, Herve D, Girault JA. DARPP-32 interaction with adducin may mediate rapid environmental effects on striatal neurons. Nat Commun. 2015; 6:10099.

56. King MM, Huang CY, Chock PB, Nairn AC, Hemmings $\mathrm{HC} \mathrm{Jr}$, Chan KF, Greengard P. Mammalian brain phosphoproteins as substrates for calcineurin. J Biol Chem. 1984; 259:8080-8083.

57. Dodge-Kafka KL, Bauman A, Mayer N, Henson E, Heredia L, Ahn J, McAvoy T, Nairn AC, Kapiloff MS. cAMP-stimulated protein phosphatase 2A activity associated with muscle A kinase-anchoring protein (mAKAP) signaling complexes inhibits the phosphorylation and activity of the cAMP-specific phosphodiesterase PDE4D3. J Biol Chem. 2010; 285:11078-11086.

58. Ahn JH, Sung JY, McAvoy T, Nishi A, Janssens V, Goris J, Greengard P, Nairn AC. The B"/PR72 subunit mediates Ca2+-dependent dephosphorylation of DARPP-32 by protein phosphatase 2A. Proc Natl Acad Sci USA. 2007; 104:9876-9881.

59. Yamada K, Takahashi S, Karube F, Fujiyama F, Kobayashi K, Nishi A, Momiyama T. Neuronal circuits and physiological roles of the basal ganglia in terms of transmitters, receptors and related disorders. J Physiol Sci. 2016; 66:435-446. 
60. Matamales M, Girault JA. Signaling from the cytoplasm to the nucleus in striatal medium-sized spiny neurons. Front Neuroanat. 2011; 5:37.

61. Liu F, Virshup DM, Nairn AC, Greengard P. Mechanism of regulation of casein kinase I activity by group I metabotropic glutamate receptors. J Biol Chem. 2002; 277:45393-45399.

62. Sams-Dodd F. Effects of dopamine agonists and antagonists on PCP-induced stereotyped behaviour and social isolation in the rat social interaction test. Psychopharmacology. 1998; 135:182-193.

63. Zheng W, Zeng Z, Bhardwaj SK, Jamali S, Srivastava LK. Lithium normalizes amphetamine-induced changes in striatal FoxO1 phosphorylation and behaviors in rats. Neuroreport. 2013; 24:560-565.

64. Ralph RJ, Paulus MP, Fumagalli F, Caron MG, Geyer MA. Prepulse inhibition deficits and perseverative motor patterns in dopamine transporter knock-out mice: differential effects of D1 and D2 receptor antagonists. J Neurosci. 2001; 21:305-313.

65. Cantrup R, Sathanantham K, Rushlow WJ, Rajakumar N. Chronic hyperdopaminergic activity of schizophrenia is associated with increased DeltaFosB levels and cdk-5 signaling in the nucleus accumbens. Neuroscience. 2012; 222:124-135.

66. Javitt DC. Glutamate and schizophrenia: phencyclidine, N-methyl-D-aspartate receptors, and dopamine-glutamate interactions. Int Rev Neurobiol. 2007; 78:69-108.

67. Pozzi L, Greco B, Sacchetti G, Leoni G, Invernizzi RW, Carli M. Blockade of serotonin 2A receptors prevents $\mathrm{PCP}$-induced attentional performance deficit and CREB phosphorylation in the dorsal striatum of $\mathrm{DBA} / 2$ mice. Psychopharmacology. 2010; 208:387-399.

68. Bonito-Oliva A, DuPont C, Madjid N, Ogren SO, Fisone G. Involvement of the Striatal Medium Spiny Neurons of the Direct Pathway in the Motor Stimulant Effects of Phencyclidine. Int J Neuropsychopharmacol. 2015.

69. O'Donnell P. Of mice and men: what physiological correlates of cognitive deficits in a mouse model of schizophrenia tell us about psychiatric disease. Neuron. 2013; 80:265-266.

70. Ishikawa $\mathrm{M}$, Mizukami $\mathrm{K}$, Iwakiri $\mathrm{M}$, Asada $\mathrm{T}$. Immunohistochemical and immunoblot analysis of Dopamine and cyclic AMP-regulated phosphoprotein, relative molecular mass 32,000 (DARPP-32) in the prefrontal cortex of subjects with schizophrenia and bipolar disorder. Prog Neuropsychopharmacol Biol Psychiatry. 2007; 31:1177-1181.

71. Zhan L, Kerr JR, Lafuente MJ, Maclean A, Chibalina MV, Liu B, Burke B, Bevan S, Nasir J. Altered expression and coregulation of dopamine signalling genes in schizophrenia and bipolar disorder. Neuropathol Appl Neurobiol. 2011; 37:206-219.
72. Kunii Y, Ikemoto K, Wada A, Yang Q, Kusakabe T, Suzuki T, Niwa S. Detailed DARPP-32 expression profiles in postmortem brains from patients with schizophrenia: an immunohistochemical study. Med Mol Morphol. 2011; 44:190-199.

73. Kunii Y, Yabe H, Wada A, Yang Q, Nishiura K, Niwa S. Altered DARPP-32 expression in the superior temporal gyrus in schizophrenia. Prog Neuropsychopharmacol Biol Psychiatry. 2011; 35:1139-1143.

74. Nishiura K, Kunii Y, Wada A, Matsumoto J, Yang Q, Ikemoto K, Niwa S. Profiles of DARPP-32 in the insular cortex with schizophrenia: a postmortem brain study. Prog Neuropsychopharmacol Biol Psychiatry. 2011; 35: 1901-1907.

75. Baracskay KL, Haroutunian V, Meador-Woodruff JH. Dopamine receptor signaling molecules are altered in elderly schizophrenic cortex. Synapse. 2006; 60:271-279.

76. Cui Y, Prabhu V, Nguyen TB, Yadav BK, Chung YC. The mRNA Expression Status of Dopamine Receptor D2, Dopamine Receptor D3 and DARPP-32 in T Lymphocytes of Patients with Early Psychosis. Int J Mol Sci. 2015; 16:26677-26686.

77. Li CH, Liao HM, Hung TW, Chen CH. Mutation analysis of DARPP-32 as a candidate gene for schizophrenia. Schizophr Res. 2006; 87:1-5.

78. Hu JX, Yu L, Shi YY, Zhao XZ, Meng JW, He G, Xu YF, Feng GY, He L. An association study between PPP1R1B gene and schizophrenia in the Chinese population. Prog Neuropsychopharmacol Biol Psychiatry. 2007; 31: 1303-1306.

79. Yoshimi A, Takahashi N, Saito S, Ito Y, Aleksic B, Usui H, Kawamura Y, Waki Y, Yoshikawa T, Kato T, Iwata N, Inada $\mathrm{T}$, Noda $\mathrm{Y}$, et al. Genetic analysis of the gene coding for DARPP-32 (PPP1R1B) in Japanese patients with schizophrenia or bipolar disorder. Schizophr Res. 2008; 100:334-341.

80. Loh HC, Tang PY, Tee SF, Chow TJ, Cheah YC, Singh SS. BDNF and DARPP-32 genes are not risk factors for schizophrenia in the Malay population. Genet Mol Res. 2012; 11:725-730.

81. Grebb JA, Girault JA, Ehrlich M, Greengard P. Chronic treatment of rats with SCH-23390 or raclopride does not affect the concentrations of DARPP-32 or its mRNA in dopamineinnervated brain regions. J Neurochem. 1990; 55:204-207.

82. Pozzi L, Hakansson K, Usiello A, Borgkvist A, Lindskog M, Greengard P, Fisone G. Opposite regulation by typical and atypical anti-psychotics of ERK1/2, CREB and Elk-1 phosphorylation in mouse dorsal striatum. J Neurochem. 2003; 86:451-459.

83. Zachariou V, Sgambato-Faure V, Sasaki T, Svenningsson P, Berton O, Fienberg AA, Nairn AC, Greengard P, Nestler EJ. Phosphorylation of DARPP-32 at Threonine-34 is required for cocaine action. Neuropsychopharmacology. 2006; 31:555-562. 
84. Bateup HS, Svenningsson P, Kuroiwa M, Gong S, Nishi A, Heintz N, Greengard P. Cell type-specific regulation of DARPP-32 phosphorylation by psychostimulant and antipsychotic drugs. Nat Neurosci. 2008; 11:932-939.

85. Bonito-Oliva A, Feyder M, Fisone G. Deciphering the Actions of Antiparkinsonian and Antipsychotic Drugs on cAMP/DARPP-32 Signaling. Front Neuroanat. 2011; 5:38.

86. Valjent E, Bertran-Gonzalez J, Bowling H, Lopez S, Santini E, Matamales M, Bonito-Oliva A, Herve D, Hoeffer C, Klann E, Girault JA, Fisone G. Haloperidol regulates the state of phosphorylation of ribosomal protein S6 via activation of PKA and phosphorylation of DARPP-32. Neuropsychopharmacology. 2011; 36:2561-2570.

87. Sanchez N, Coura R, Engmann O, Marion-Poll L, Longueville S, Herve D, Andres ME, Girault JA. Haloperidol-induced Nur77 expression in striatopallidal neurons is under the control of protein phosphatase 1 regulation by DARPP-32. Neuropharmacology. 2014; 79:559-566.

88. Levesque D, Rouillard C. Nur77 and retinoid X receptors: crucial factors in dopamine-related neuroadaptation. Trends Neurosci. 2007; 30:22-30.

89. Chen Q, Wang H, Liao S, Gao Y, Liao R, Little PJ, $\mathrm{Xu}$ J, Feng ZP, Zheng Y, Zheng W. Nerve growth factor protects retinal ganglion cells against injury induced by retinal ischemia-reperfusion in rats. Growth factors. 2015; 33:149-159.

90. Wang H, Wang R, Thrimawithana T, Little PJ, Xu J, Feng ZP, Zheng W. The nerve growth factor signaling and its potential as therapeutic target for glaucoma. Biomed Res Int. 2014; 2014:759473.

91. Wang H, Duan X, Ren Y, Liu Y, Huang M, Liu P, Wang R, Gao G, Zhou L, Feng Z, Zheng W. FoxO3a negatively regulates nerve growth factor-induced neuronal differentiation through inhibiting the expression of neurochondrin in PC12 cells. Mol Neurobiol. 2013; 47:24-36.

92. Fernandes BS, Steiner J, Berk M, Molendijk ML, GonzalezPinto A, Turck CW, Nardin P, Goncalves CA. Peripheral brain-derived neurotrophic factor in schizophrenia and the role of antipsychotics: meta-analysis and implications. Mol Psychiatry. 2015; 20:1108-1119.

93. Qin XY, Wu HT, Cao C, Loh YP, Cheng Y. A meta-analysis of peripheral blood nerve growth factor levels in patients with schizophrenia. Mol Psychiatry. 2017.

94. Leggio GM, Salomone S, Bucolo C, Platania C, Micale V, Caraci F, Drago F. Dopamine D receptor as a new pharmacological target for the treatment of depression. Eur J Pharmacol. 2013; 719:25-33.

95. Angelucci F, Mathe AA, Aloe L. Neurotrophic factors and CNS disorders: findings in rodent models of depression and schizophrenia. Prog Brain Res. 2004; 146:151-165.

96. Schenkel LC, Segal J, Becker JA, Manfro GG, Bianchin MM, Leistner-Segal S. The BDNF Val66Met polymorphism is an independent risk factor for high lethality in suicide attempts of depressed patients. Prog Neuropsychopharmacol Biol Psychiatry. 2010; 34:940-944.

97. Pandey GN, Ren X, Rizavi HS, Conley RR, Roberts RC, Dwivedi Y. Brain-derived neurotrophic factor and tyrosine kinase $\mathrm{B}$ receptor signalling in post-mortem brain of teenage suicide victims. Int J Neuropsychopharmacol. 2008; 11:1047-1061.

98. Chen ZY, Jing D, Bath KG, Ieraci A, Khan T, Siao CJ, Herrera DG, Toth M, Yang C, McEwen BS, Hempstead BL, Lee FS. Genetic variant BDNF (Val66Met) polymorphism alters anxiety-related behavior. Science. 2006; 314:140-143.

99. Egan MF, Kojima M, Callicott JH, Goldberg TE, Kolachana BS, Bertolino A, Zaitsev E, Gold B, Goldman D, Dean M, Lu B, Weinberger DR. The BDNF val66met polymorphism affects activity-dependent secretion of BDNF and human memory and hippocampal function. Cell. 2003; 112:257-269.

100. Muglia P, Vicente AM, Verga M, King N, Macciardi F, Kennedy JL. Association between the BDNF gene and schizophrenia. Mol Psychiatry. 2003; 8:146-147.

101. Zai CC, Manchia M, Sonderby IE, Yilmaz Z, De Luca V, Tiwari AK, Squassina A, Zai GC, Shaikh SA, Strauss J, King N, Le Foll B, Kaplan AS, et al. Investigation of the genetic interaction between BDNF, DRD3 genes in suicidical behaviour in psychiatric disorders. World J Biol Psychiatry. 2015; 16:171-179.

102. Kheirollahi M, Kazemi E, Ashouri S. Brain-Derived Neurotrophic Factor Gene Val66Met Polymorphism and Risk of Schizophrenia: A Meta-analysis of Case-Control Studies. Cell Mol Neurobiol. 2016; 36:1-10.

103. Zakharyan R, Atshemyan S, Gevorgyan A, Boyajyan A. Nerve growth factor and its receptor in schizophrenia. BBA Clin. 2014; 1:24-29.

104. Meyer-Lindenberg A, Straub RE, Lipska BK, Verchinski BA, Goldberg T, Callicott JH, Egan MF, Huffaker SS, Mattay VS, Kolachana B, Kleinman JE, Weinberger DR. Genetic evidence implicating DARPP-32 in human frontostriatal structure, function, and cognition. J Clin Invest. 2007; 117:672-682.

105. Ivkovic S, Polonskaia O, Farinas I, Ehrlich ME. Brainderived neurotrophic factor regulates maturation of the DARPP-32 phenotype in striatal medium spiny neurons: studies in vivo and in vitro. Neuroscience. 1997; 79:509-516.

106. Guibinga GH, Barron N, Pandori W. Striatal neurodevelopment is dysregulated in purine metabolism deficiency and impacts DARPP-32, BDNF/TrkB expression and signaling: new insights on the molecular and cellular basis of Lesch-Nyhan Syndrome. PLoS One. 2014; 9:e96575.

107. Bogush A, Pedrini S, Pelta-Heller J, Chan T, Yang Q, Mao Z, Sluzas E, Gieringer T, Ehrlich ME. AKT and CDK5/ p35 mediate brain-derived neurotrophic factor induction of 
DARPP-32 in medium size spiny neurons in vitro. J Biol Chem. 2007; 282:7352-7359.

108. Prathikanti S, Weinberger DR. Psychiatric genetics - the new era: genetic research and some clinical implications. Br Med Bull. 2005; 73-74:107-122.

109. Nishi A, Shuto T. Potential for targeting dopamine/ DARPP-32 signaling in neuropsychiatric and neurodegenerative disorders. Expert Opin Ther Targets. 2017:1-14.

110. Kuroiwa M, Snyder GL, Shuto T, Fukuda A, Yanagawa Y, Benavides DR, Nairn AC, Bibb JA, Greengard P, Nishi A. Phosphodiesterase 4 inhibition enhances the dopamine D1 receptor/PKA/DARPP-32 signaling cascade in frontal cortex. Psychopharmacology. 2012; 219:1065-1079.

111. Zhang MZ, Zhou ZZ, Yuan X, Cheng YF, Bi BT, Gong MF, Chen YP, Xu JP. Chlorbipram: a novel PDE4 inhibitor with improved safety as a potential antidepressant and cognitive enhancer. Eur J Pharmacol. 2013; 721:56-63.

112. Guo H, Cheng Y, Wang C, Wu J, Zou Z, Niu B, Yu H, Wang H, Xu J. FFPM, a PDE4 inhibitor, reverses learning and memory deficits in APP/PS1 transgenic mice via cAMP/PKA/CREB signaling and anti-inflammatory effects. Neuropharmacology. 2017; 116:260-269.

113. Zhou ZZ, Cheng YF, Zou ZQ, Ge BC, Yu H, Huang C, Wang HT, Yang XM, Xu JP. Discovery of N-Alkyl Catecholamides as Selective Phosphodiesterase-4 Inhibitors with Anti-neuroinflammation Potential Exhibiting Antidepressant-like Effects at Non-emetic Doses. ACS Chem Neurosci. 2017; 8:135-146.
114. Belkhiri A, Zhu S, El-Rifai W. DARPP-32: from neurotransmission to cancer. Oncotarget. 2016; 7:1763117640. doi: 10.18632/oncotarget. 7268 .

115. Romero E, Ali C, Molina-Holgado E, Castellano B, Guaza C, Borrell J. Neurobehavioral and immunological consequences of prenatal immune activation in rats. Influence of antipsychotics. Neuropsychopharmacology. 2007; 32:1791-1804.

116. Liu DY, Shen XM, Yuan FF, Guo OY, Zhong Y, Chen JG, Zhu LQ, Wu J. The Physiology of BDNF and Its Relationship with ADHD. Mol Neurobiol. 2015; 52:1467-1476.

117. Wang H, Quirion R, Little PJ, Cheng Y, Feng ZP, Sun HS, $\mathrm{Xu}$ J, Zheng W. Forkhead box $\mathrm{O}$ transcription factors as possible mediators in the development of major depression. Neuropharmacology. 2015; 99:527-537.

118. Wang H, Zhang Q, Wen Q, Zheng Y, Lazarovici P, Jiang H, Lin J, Zheng W. Proline-rich Akt substrate of $40 \mathrm{kDa}$ (PRAS40): a novel downstream target of PI3k/Akt signaling pathway. Cell Signal. 2012; 24:17-24.

119. Harrisberger F, Smieskova R, Schmidt A, Lenz C, Walter A, Wittfeld K, Grabe HJ, Lang UE, Fusar-Poli P, Borgwardt S. BDNF Val66Met polymorphism and hippocampal volume in neuropsychiatric disorders: A systematic review and meta-analysis. Neurosci Biobehav Rev. 2015; 55:107-118.

120. Sanada K, Zorrilla I, Iwata Y, Bermudez-Ampudia C, GraffGuerrero A, Martinez-Cengotitabengoa M, Gonzalez-Pinto A. The Efficacy of Non-Pharmacological Interventions on BrainDerived Neurotrophic Factor in Schizophrenia: A Systematic Review and Meta-Analysis. Int J Mol Sci. 2016; 17. 